\title{
Photovoltaics Can AdD Capacity TO THE UTILITY GRID
}

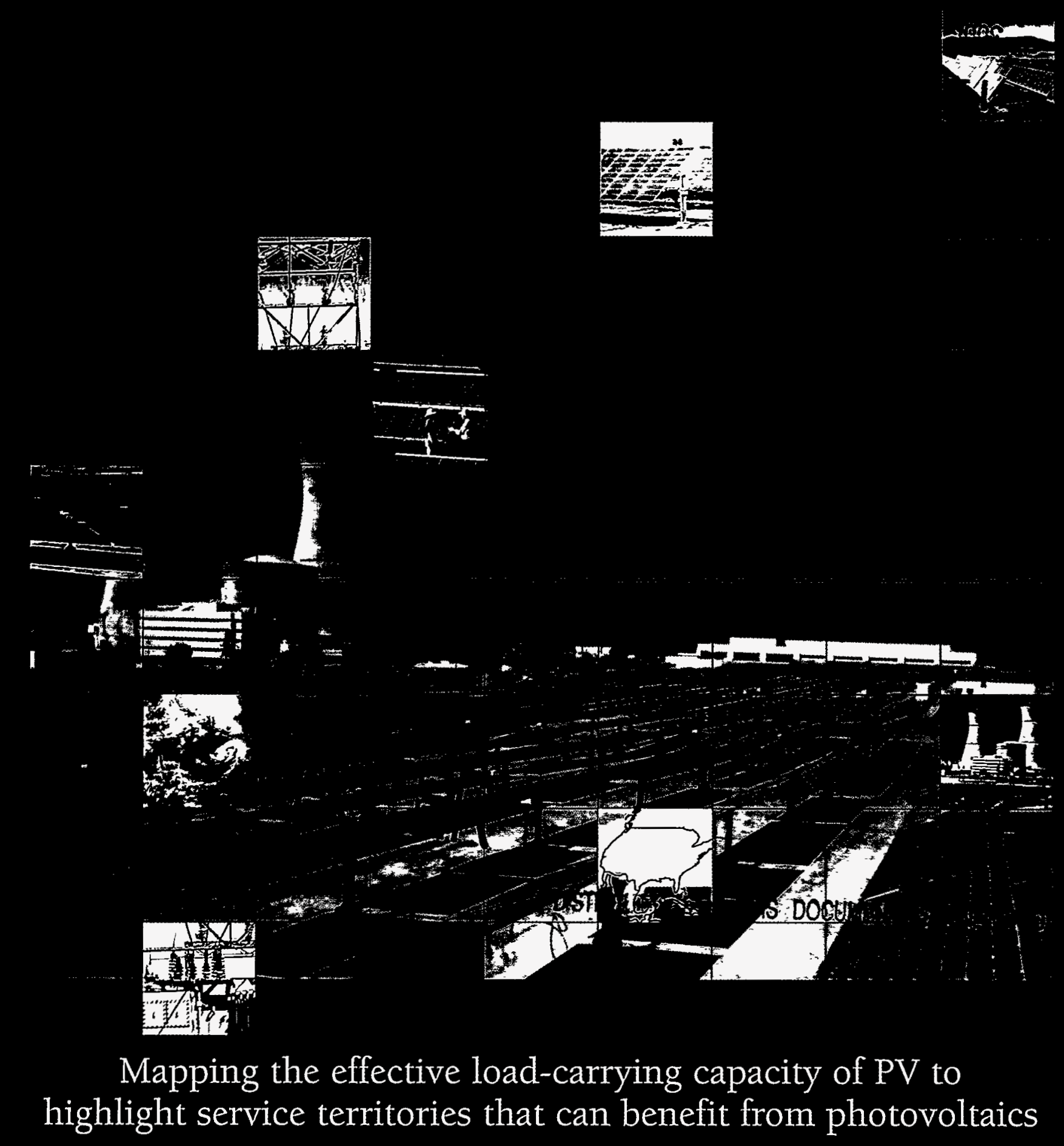




\section{PV ISN'T JUST AN ENERGY SOURCE}

Photovoltaics (PV) can contribute to or receive credit for a utility's capacity. But how is this possible for a power source that is not dispatchable? The key is that many applications that require energy and drive a utility's load are synchronous with the intensity of the solar resource.

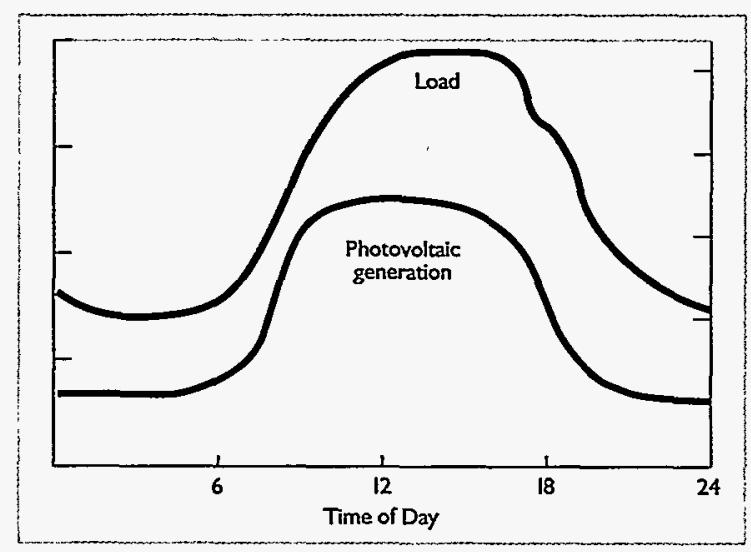

Utility load and PV output versus time of day
Therefore, we want to determine the locations where PV can provide power when it is needed. For these areas, we can consider PV as more than an energy source-it also contributes to a utility's capacity.

In other words, the value of PV to a utility's capacity depends on load matching: the value is greatest when PV power output most closely matches the utility's load requirements.

\section{FIRST, LET'S DEFINE} A FEW TERMS

Effective load-carrying capacity (ELCC) is the ability of a power generator-whether PV or conventional-to effectively contribute to a utility's capacity, or system output, to meet its load. Therefore, ELCC for a photovoltaic system represents PV's ability to provide power to the utility when it is needed. It is the capacity credit of the PV power plant.

A typical example of high ELCC for PV occurs when the utility system load reflects commercial customers' demand for midday air-conditioning; this load is a good match to PV's power output. The PV ELCC is lower for residential customers who have a high airconditioning demand in the late afternoon; the load is not matched as well to the intensity of the solar resource.

Summer-to-winter peak-load (SWP) ratio is another parameter that must be understood to appreciate the true value of PV to a utility. This parameter-based strictly on the characteristic shape of the utility's load-compares the peak summer demand to the peak winter demand.

A high SWP ratio, say 1.25 or greater, indicates that summertime demand greatly exceeds wintertime demand. The greater the SWP ratio, the more closely the load is likely to match the actual solar resource. This is because the solar resource is much greater in the summer-hours of sunlight are longer and the intensity of the sun is greater because it is higher in the sky.
So, How Do WE DETERMINE ELCC?

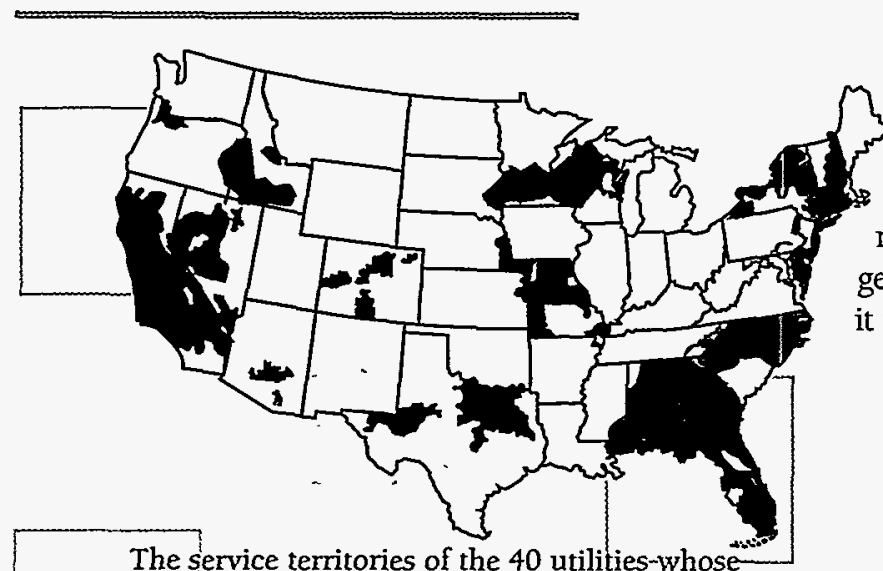

The service territories of the 40 utilities-
loads were used to determine PV ELCC.
Much information is available about the distribution of the solar resource across the United States, but until recently, little has been available on the distribution of PV'S ELCC. Therefore, we have developed a method to determine how closely utility load requirements match PV's ability to generate power when it is needed.
We started with a 2-year set of hourly load data for 40 utilities whose service territories covered different sections of the country. Then, using information from geostationary satellites, we estimated PV power generation at points in time and space that coincided with the load data.

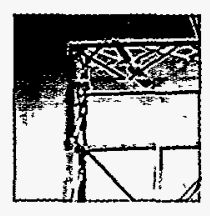




\section{DISCLAIMER}

Portions of this document may be illegible in electronic image products. Images are produced from the best available original document. 


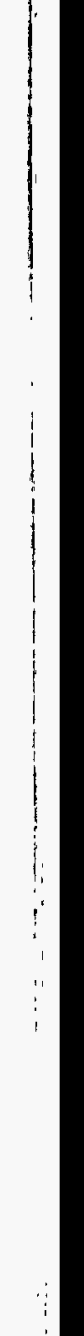




\section{DISCLAIMER}

This report was prepared as an account of work sponsored by an agency of the United States Government. Neither the United States Government nor any agency thereof, nor any of their employees, makes any warranty, express or implied, or assumes any legal liability or responsibility for the accuracy, completeness, or usefulness of any information, apparatus, product, or process disclosed, or represents that its use would not infringe privately owned rights. Reference herein to any specific commercial product, process, or service by trade name, trademark, manufacturer, or otherwise does not necessarily constitute or imply its endorsement, recommendation, or favoring by the United States Government or any agency thereof. The views and opinions of authors expressed herein do not necessarily state or reflect those of the United States Government or any agency thereof. 
1 
WHAT DOES THE ELCC METHOD TELL US?
The intensity of the solar resource is obviously critical to PV power generation. But in determining PVs value to a utility, the magnitude of the sun's intensity is less important than its relationship to load requirements.

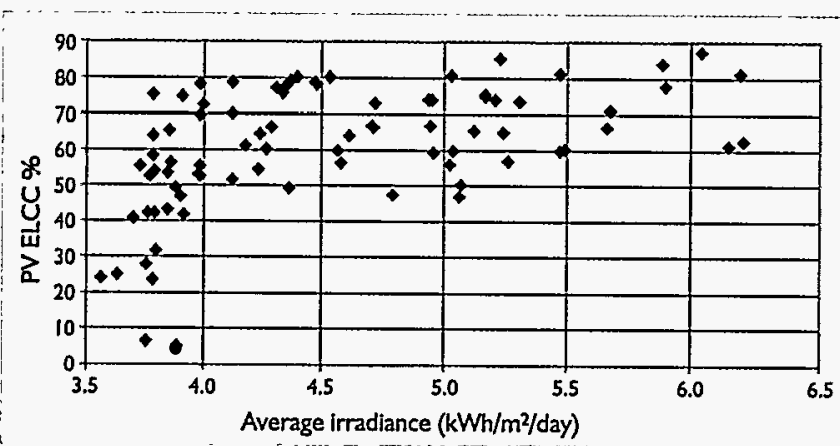

$\checkmark$ The PVELCC is not related to overall solar energy output.

However, the PV ELCC is highly correlated with load-shape characteristics.

In fact, all utilities studied-whether winter-peaking or highly summerpeaking-fit the pattern that shows PV ELCC increasing as a function of increasing SWP ratio.

ELCC may exceed $80 \%$ of the rated PV output when the load is driven by the sun, for example, when the SWP ratio is above 1.5. In that case, a 1-kilowatt PV system would have an ELCC of 800 watts. In other words, a PV system rated at 1 kilowatt could be considered a dispatchable power source of 800 watts.

PV ELCC \% vs, solar intensity
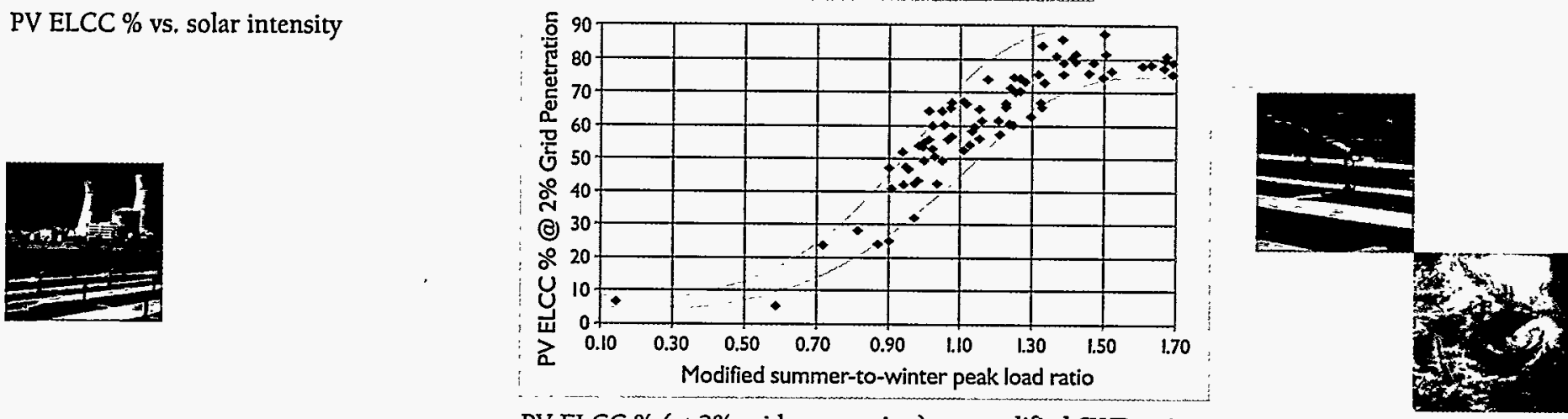

PV ELCC \% (at 2\% grid penetration) vs. modified SWP ratio

CAN YOU Picture THE ELCC OF PV ACROSS THE UNITED STATES?

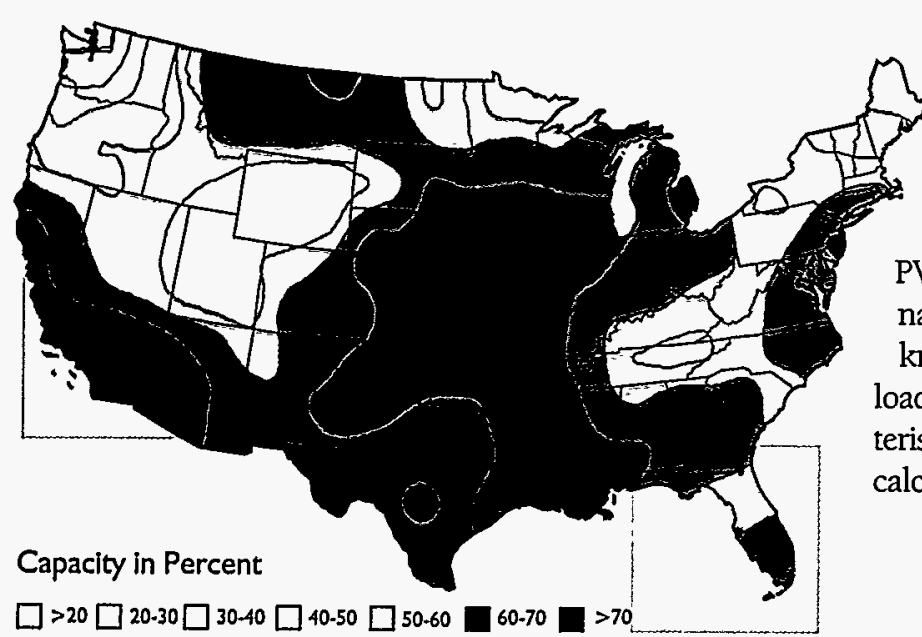

This load-shape relationship provides an analytical tool that allows us to map the distribution of PV's ELCC across the nation. That is, by knowing a utility's load-shape characteristics, we can calculate an
SWP ratio and determine an ELCC value for PV. Using SWP ratios from some 500 U.S. utilities, we applied this method to determine the PV ELCC values, which were then plotted, gridded, and contoured to produce the map at left. To continue to refine this method, we are studying other PV grid-penetration levels, refining the relationship between load shape and PV ELCC, and analyzing multiyear, monthly, and customer trends.

PV ELCC map of U.S. (based on 500 utility loads) 
PV's Value as a

\section{TECHNOLOGY}

THAT ADDS

CAPACITY

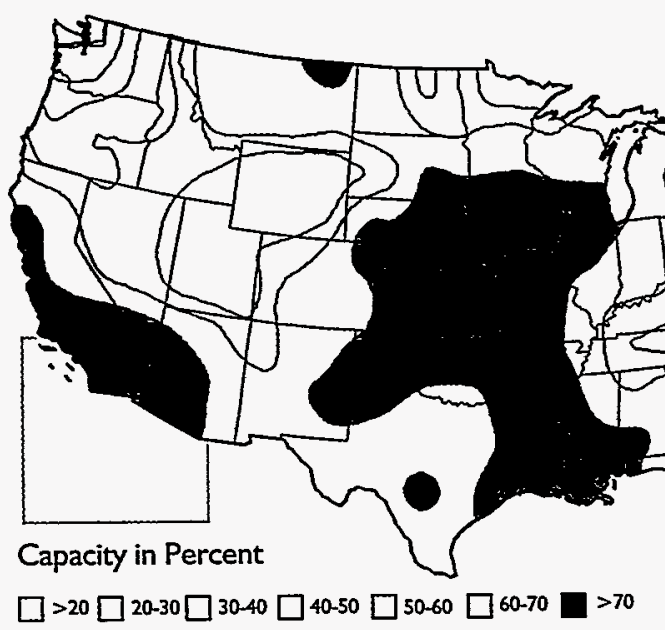

PV ELCC map of U.S. (based on 500 utility loads)
- PV has tangible value to utilities in generating capacity.

- Regions of high ELCC do not always overlap with regions traditionally targeted for solar energy. For example, note the high ELCC values in southern California, the central states, and the Mid-Atlantic seaboard states. The "traditional solar areas" of Florida and the arid Southwest states have lower PV ELCC values despite their greater solar<smiles>C1CCCC1</smiles>

intensity values, because PV output doesn't match the loads as well in those areas.

- Areas of high PV ELCC are associated with regions that have certain characteristics:

- Intense summer heat waves

- High daytime commercial demand

- Small electric-heating demand.

- Isolated pockets with high PV ELCC values may exist within a region having lower PV ELCC values. For example, high-density urban areas may have a high daytime demand in the commercial sector and thus have a high ELCC value for PV.

These new findings about PVs ELCC should make decisions on capacity additions and demand management a little easier for U.S. utilities.

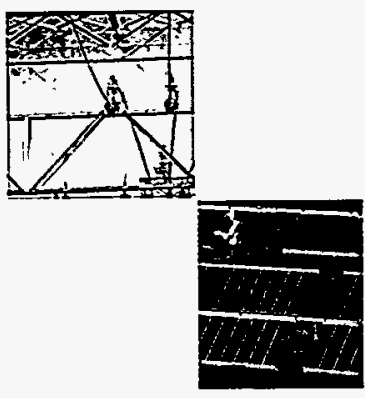

FOR MORE INFORMATION, CONTACT:

The State University of New York at Albany,

Atmospheric Sciences Research Center

Richard Perez and Robert Seals

(518) 442-3808

(518) $442-9071$ (fax)

e-mail: perez@asrc.albany.edu

Christy Herig

National Renewable Energy Laboratory

Center for Photovoltaics and Electronic Materials

(303) $384-6546$

(303) $384-6490$ (fax)

e-mail: herigc@tcplink.nrel.gov

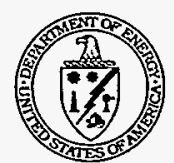

Produced for the U.S. Department of Energy

1000 Independence Ave., S.W.

Washington, D.C. 20585

by the National Renewable Energy Laboratory, a DOE national laboratory.

DOE/GO-10096-262

DE96000544

September 1996

Photographs appearing throughout this brochure: PIX00009/Warren Gretz, NREL; PIX00015/Roger Taylor; PIX00016/Roger Taylor; PIX0018I/Warren Gretz, NREL; PIX01026/Sacramento Municipal Utility District (SMUD); and PIX 03657/ENTECH. Thanks to NREI's Center for Renewable Energy Resources for contoured maps.

Printed with a biodegradable ink on paper containing at least $50 \%$ wastepaper, including $20 \%$ postconsumer waste. 